\title{
CONGENITAL TRICUSPID INCOMPETENCE
}

BY

\author{
D. W. BARRITT AND H. URICH
}

From the Departments of Medicine and Pathology, University of Bristol

Congenital tricuspid incompetence is rare and the following case is, therefore, worthy of mention.

\section{Case Report}

A boy of four years was first referred to the school cardiac clinic on account of a murmur heard at a routine examination. He had had pneumonia a year previously. He had not yet begun to talk. On examination at that time there was no cyanosis. A loud systolic murmur, accompanied by a thrill, was heard at the apex. An orthodiagram of the heart shadow showed prominence of the right auricle in the P.A. view. The cardiogram showed sinus rhythm with right bundle-branch block. He was seen at yearly intervals and at the age of 10 cardiac enlargement was detected clinically. The thrill and murmur were unchanged. The cardiogram again showed sinus rhythm and right bundle-branch

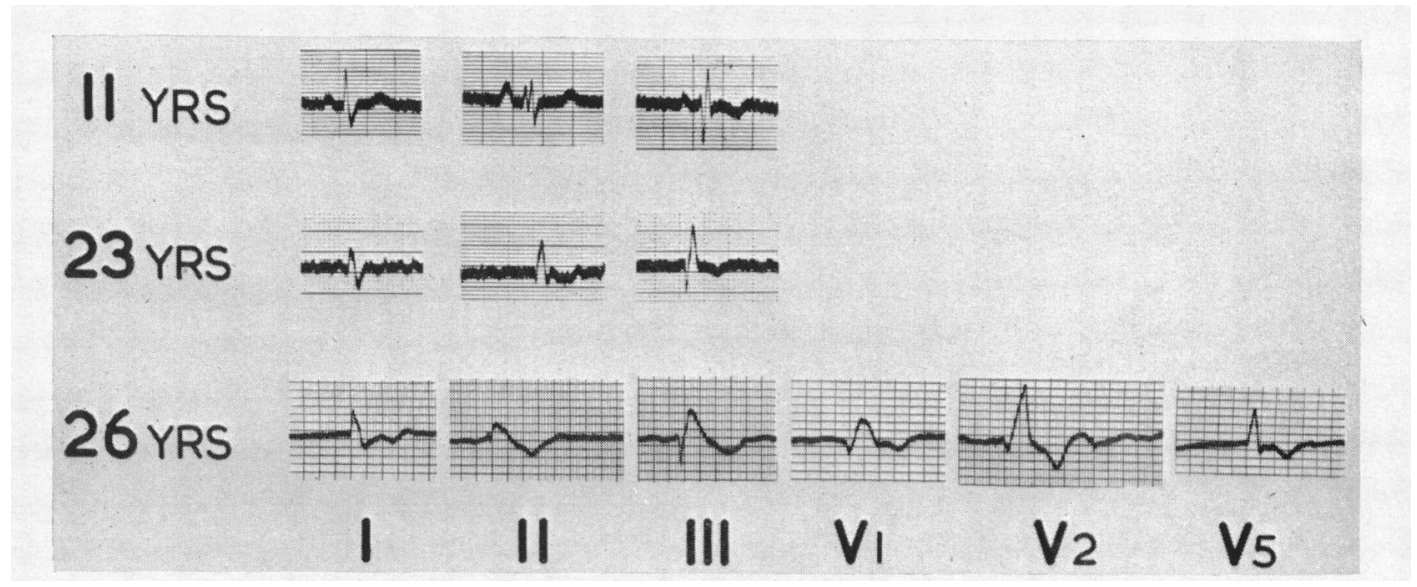

FIG. 1.-Serial electrocardiograms in congenital tricuspid incompetence.

block. The chest X-ray showed generalized cardiac enlargement and diminished pulmonary artery shadows. He left school at 14 years and was then noticed to have blue lips and hands, but no finger clubbing. Sinus rhythm was still present. When next seen at 22 years he was working as a milk roundsman. His blueness was more marked but there was still no clubbing. The heart was now much enlarged (Fig. 2). The systolic thrill and murmur were unchanged. For the first time a very striking systolic pulsation was noted in the neck veins. There was also marked systolic pulsation of an enlarged liver. Auricular fibrillation was now established. In the next five years the heart progressively increased in size. The neck veins became more prominent, and a large mass of tortuous veins extended from the neck over the clavicles. Systolic pulsation was always most striking and a similar pulsation could be felt over a grossly enlarged liver. The systolic thrill and murmur gradually diminished and were finally lost. He remained cyanosed, but showed no finger clubbing. At the age of 25 his hæmoglobin was 120 per cent and arterial oxygen saturation 90 per cent. 


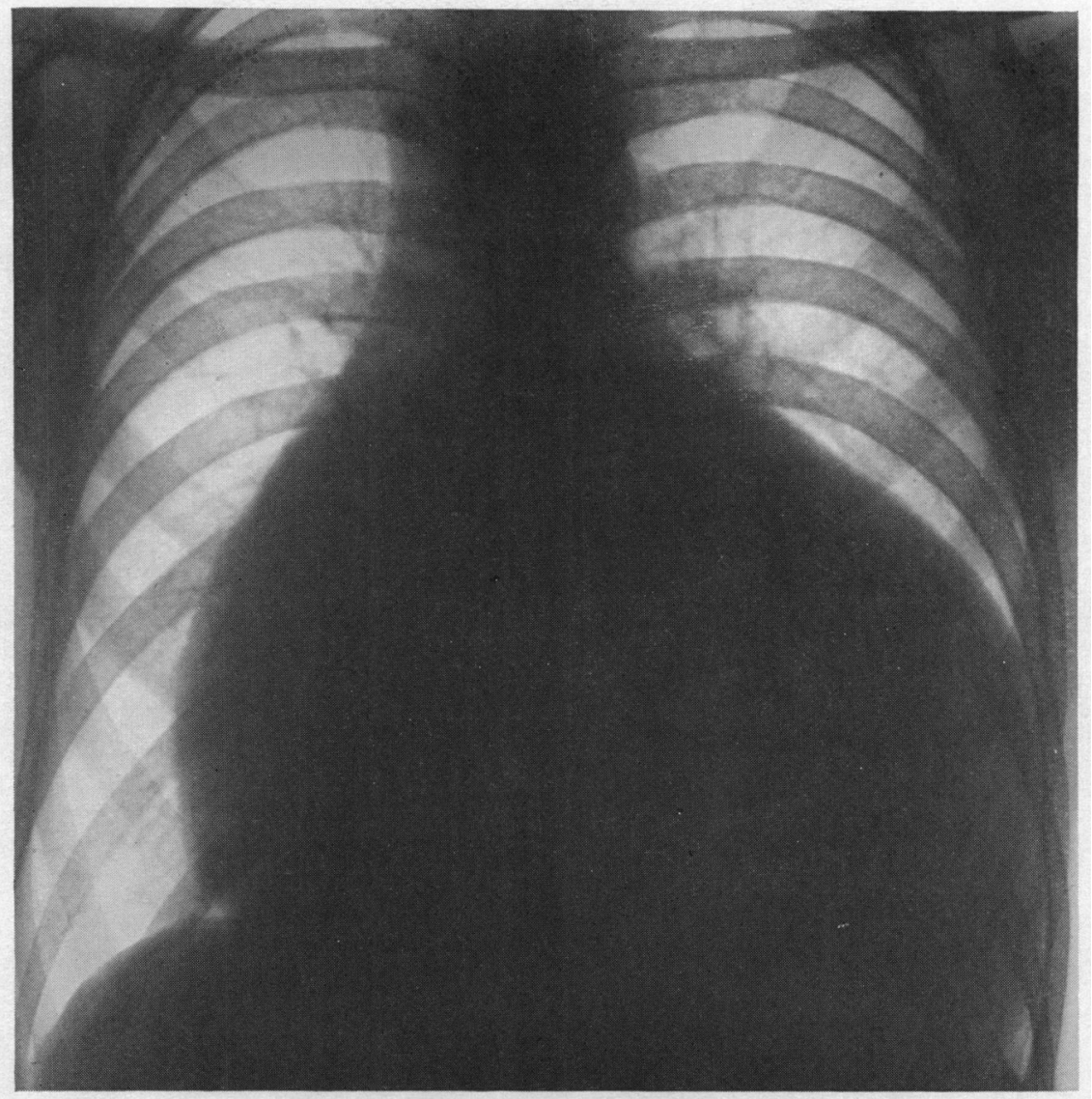

FIG. 2.-The chest radiogram at 24 years of age, showing great enlargement of the heart and small pulmonary artery shadows.

In the last two years of his life he was admitted several times to hospital with acute respiratory infections. CEdema of the ankles and ascites became gross. He was progressively more disabled, and died at the age of 28 of congestive heart failure.

Post-Mortem Findings. The subject was a thin young man in severe congestive heart failure with œdema, gross ascites, small bilateral pleural effusions and chronic venous congestion of all organs. The pericardial cavity contained about $100 \mathrm{ml}$. of bloodstained fluid. Both visceral and parietal surfaces were covered with shaggy fibrinous deposit. There were no adhesions. The heart weighed $700 \mathrm{~g}$. The right atrium was enormously dilated and hypertrophied and received grossly dilated superior and inferior venæ cavæ and coronary sinus. There was mural thrombus in the auricular appendage. The right A-V orifice was enormously dilated (circumference $26 \mathrm{~cm}$.). The tricuspid valve consisted of two cusps, anterior and fused postero-septal, both attached to the A-V wall by short and slender endocardial cords which immobilized the cusps (Fig. 3). The chordæ tendineæ were short and slender and were attached to two papillary muscles of which the posterior was small and rudimentary. The right ventricle was grossly dilated and hypertrophied (thickness $1.1 \mathrm{~cm}$.), the enlargement involving predominantly the inflow tract. The pulmonary orifice and valve were normal. The left atrium was normal apart from slight endocardial thickening. The left A-V orifice was normal (circumference $9 \mathrm{~cm}$.). The mitral valve showed some thickening and nodularity of the cusps, but no shortening or fusion. There were several flat yellowish vegetations distributed irregularly along the cusp margins and spreading on to slightly thickened chordæ tendineæ. The left ventricle was normal (thickness $1.3 \mathrm{~cm}$.). The aortic valve showed a few flat yellowish vegetations near the cusp margins, but was otherwise normal. The interauricular and interventricular septa and the ductus 


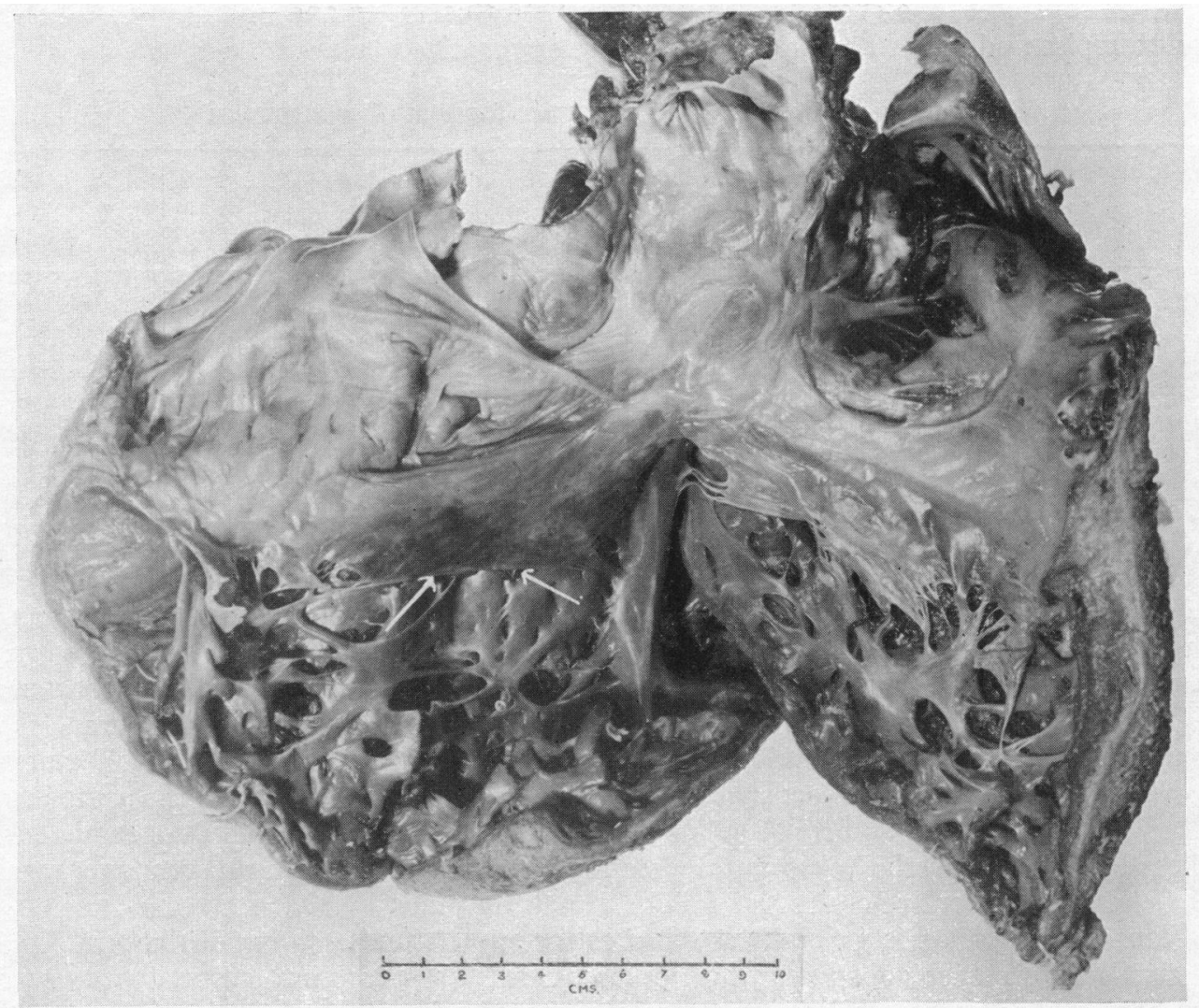

FIG. 3.-The dilated right ventricular cavity, showing the two cusps at the A-V orifice. The posterior cusp is seen to be tethered to the ventricular wall by short chordæ at its free margin.

arteriosus were closed. The aorta was somewhat hypoplastic and showed a few patches of fatty atheroma. The coronary arteries were free from atheroma. The pulmonary artery was of normal size and free from atheroma. The systemic veins were grossly dilated and tortuous veins formed a varicose plexus.

Histology of Heart. The pericardium showed fibroblastic proliferation with organization of the fibrinous exudate, but only minimal lymphocytic infiltration. There was severe venous and capillary congestion with numerous small hæmorrhages. The myocardium was normal. There were no Aschoff bodies or scars. The endocardium showed thickening of the mitral valve with normal arrangement of collagen fibres. The vegetations on the mitral and aortic valves and papillary muscles consisted of laminated thrombus which had undergone partial organization. The chordæ tendineæ were surrounded by concentric deposits of loose collagen. There were no inflammatory lesions either in the valves or the vegetations. No organisms could be seen in the vegetations.

\section{Discussion}

The earlier reports as reviewed by Herxheimer (1910) show confusion between incompetence of the valve and the Ebstein malformation. Abbott (1936) distinguished clearly between downward displacement of the valve (Ebstein's disease) and incomplete differentiation of the cusps leading to true incompetence, and describes one case of the latter. Other cases have been described by Hotz (1923), Ariel (1930), Dubin and Hollingshead (1944) and Palladino and Kinney (1948) who described two cases. Only one of these patients reached adult life. Of the cases described only two cusps were present in two instances, the cusps were tethered tightly to the ventricular wall in 
three, and in four cases the cusps were misshapen with thickening and nodularity. The features of these examples and of the case now reported are summarized below.

Pathological Features of Congenttal Tricuspid Incompetence

\begin{tabular}{|c|c|c|c|c|c|c|}
\hline Author & Sex & Age & $\begin{array}{c}\text { Number } \\
\text { of } \\
\text { cusps }\end{array}$ & $\begin{array}{l}\text { Tethering } \\
\text { of } \\
\text { cusps }\end{array}$ & $\begin{array}{l}\text { Thickening } \\
\text { and } \\
\text { nodularity }\end{array}$ & $\begin{array}{l}\text { Condition } \\
\text { of mitral } \\
\text { valve }\end{array}$ \\
\hline $\begin{array}{l}\text { Abbott (1936) } \\
\text { Hotz (1923) } \\
\text { Ariel (1930) } \\
\text { D and H (1944) } \\
\text { P and K I (1948) } \\
\text { P and K II (1948) } \\
\text { B and U (1956) }\end{array}$ & $\begin{array}{l}\mathbf{M} \\
\mathbf{F} \\
\mathbf{M} \\
\mathbf{F} \\
\mathbf{M} \\
\mathbf{M} \\
\mathbf{M}\end{array}$ & $\begin{array}{l}7 \text { days } \\
13 \text { yr. } \\
2 \text { days } \\
5 \text { min. } \\
34 \text { yr. } \\
3 \text { mth. } \\
28 \text { yr. }\end{array}$ & $\begin{array}{l}3 \\
2 \\
3 \\
2 \\
3 \\
3 \\
2\end{array}$ & $\begin{array}{l}\text { No } \\
\text { No } \\
\text { No } \\
\text { Yes } \\
\text { Yes } \\
\text { Yes } \\
\text { Yes }\end{array}$ & $\begin{array}{c}\text { Gross } \\
\text { Present } \\
\text { Gross } \\
\text { Slight } \\
\text { Slight } \\
\text { No } \\
\text { No }\end{array}$ & $\begin{array}{c}\text { Normal } \\
\text { Normal } \\
\text { Grossly affected } \\
\text { Normal } \\
\text { Normal } \\
\text { Normal } \\
\text { Slight nodular } \\
\text { thickening }\end{array}$ \\
\hline
\end{tabular}

The diagnosis of this condition rests on the classical signs of tricuspid incompetence, the knowledge that a cardiac abnormality was present at an early age and the exclusion of the other causes of organic and functional tricuspid incompetence. In this case the physical signs were gross, the murmur was first heard at four years of age, and there was never any evidence of mitral stenosis or pulmonary hypertension. The cardiogram was characterized by right bundle-branch block; sinus rhythm later gave way to auricular fibrillation. Radiologically the striking features were progressive enlargement of the heart shadow which ultimately occupied almost the complete transverse diameter of the chest, and small pulmonary artery shadows. In spite of a steadily enlarging heart the patient remained relatively symptomless until the early twenties. Gross venous engorgement preceded the development of congestive failure by several years.

The cause of the lesion is generally ascribed to incomplete undermining of the primitive endocardial cushions by sinusoidal spaces which differentiate the cushions into cusps, chordæ tendineæ, and papillary muscles. The thickening and nodularity may be due to defective absorption of the substance of the cushions, but hyperplasia of the cushions has been suggested as an explanation.

Two other features of the case require comment. The endocardial vegetations appear to be due to a terminal non-infective deposition of endocardial thrombi found occasionally at autopsy on subjects debilitated by a prolonged illness (the "marantic thrombi" of older writers). The thickening of the chordæ tendineæ was shown to be due to recent deposition of collagen, almost certainly the result of organization of previous thrombi of the same nature. The pericarditis is more difficult to explain in the absence of rheumatism, tuberculosis, pyogenic infection or uræmia. It may possibly have been a reaction to extravasation of blood from grossly engorged coronary veins.

\section{Summary}

A case of congenital tricuspid incompetence is described and the previously reported cases are briefly reviewed.

We are grateful to Professor C. Bruce Perry, Dr. H. J. Orr-Ewing and Professor T. F. Hewer for permission to publish this case, and for their help and advice.

\section{References}

Abbott, Maude E. (1936). Atlas of Congenital Cardiac Disease, p. 24. New York, American Heart Association. Ariel, M. B. (1930). Virchow's Arch., 277, 501.

Dubin, I. N., and Hollinshead, W. H. (1944). Arch. Path., 38, 225.

Herxheimer, G. (1910) in Swalbe: Die Morphologie der Missbildungen des Menschen und der Tiere, Vol. III, 2, p. 474. Jena, Gustav Fischer.

Hotz, A. (1923). Jahr. Kinderheil, 102, 1. "

Palladino, Y.. S., and Kinney, T. D. (1948). Bull. Int. Ass. med. Mus., 28, 23. 